\title{
Veterans' attitudes regarding a database for genomic research
}

\author{
David Kaufman, $P h D^{I}$, Juli Murphy, $M S^{I}$, Lori Erby, $P h D^{2}$, Kathy Hudson, $P h D^{I}$, \\ and Joan Scott, MS, CGC
}

\begin{abstract}
Purpose: Large cohort studies to investigate interactions between genes, environment, and lifestyle require large representative samples of the population. The Department of Veterans Affairs health care system is uniquely positioned to carry out such research, with a large patient population and a sophisticated system of electronic medical records. As Veterans Affairs considers establishing a large database of genetic information and medical records for research purposes, a survey of 931 Veterans Affairs patients was carried out to measure their willingness to participate, what their concerns would be, and their preferences about some aspects of study design. Methods: A sample of veterans who receive Veterans Affairs health care was surveyed online in April and May of 2008. The proposed genomic study was described to respondents, who then were asked about their support for the study and willingness to participate, and their opinions about the study and some of its components. A descriptive analysis examined differences in attitudes among demographic groups, and whether general beliefs were associated with support or willingness to participate. Results: Most respondents $(83 \%)$ said the database should definitely or probably be created, and overall, $71 \%$ said they would definitely or probably participate. Conclusion: Majorities of Veterans Affairs health patients in a broad range of demographic groups supported the establishment of a genomic database and showed willingness to participate. Although the desire to learn about one's own health from the study was high, altruistic characteristics were strongly related to whether or not veterans would participate. Genet Med 2009:11(5):329-337.
\end{abstract}

Key Words: veterans, genomics, public opinion, United States Department of Veterans Affairs, public policy

arge prospective cohort studies and biobanks are becoming Lstandard research tools to examine the influence and interactions of genes, environment, and lifestyle on health and disease. ${ }^{1-6}$ These studies collect DNA and other biological samples, and obtain prospective clinical information on participants. The amount and type of clinical data collected, and the methods by which these data are obtained, vary among biobanks. Some of these databases follow participants over time and periodically ask participants for updates on their health.

From the ${ }^{1}$ Genetics and Public Policy Center, Johns Hopkins University, Washington, DC; and ${ }^{2}$ Department of Health, Behavior and Society, The Johns Hopkins Bloomberg School of Public Health, Baltimore, Maryland.

David Kaufman, PhD, Genetics and Public Policy Center, 1717 Massachusetts Avenue NW, Suite 530, Washington, DC 20036. E-mail: dkaufma2@ jhu.edu.

Disclosure: The authors declare no conflict of interest.

Supplemental digital content is available for this article. Direct URL citations appear in the printed text and are provided in the HTML and PDF versions of this article on the journal's Web site (www.geneticsinmedicine.org).

Submitted for publication November 19, 2008

Accepted for publication December 19, 2008.

DOI: 10.1097/GIM.0b013e31819994f8
Some link genomic and other exposure data to electronic medical records, which can streamline data collection but may limit the information available to that recorded within a particular medical records system. Others perform standardized health exams and collect medical histories at baseline and follow-up intervals. ${ }^{7-9}$ This approach may lead to more complete data, but also may require more time and expense. All such studies face the challenge of accurately and efficiently measuring participants' environmental exposures.

In prospective research, phenotypes, genotypes, and environmental exposures can be compared among those who do and do not develop a given disease over the life of the study. Studies involving hundreds of thousands of participants are gaining favor because large sample sizes are needed to detect genes, and factors that interact with genes that confer modest increases in disease risks. Both private concerns ${ }^{1,4,5,10,11}$ and public entities are investing in these large-scale studies. ${ }^{3,9}$ As genotyping and computational tools become more affordable, ongoing studies that were initially started without a genomic focus have begun to integrate genetic data collection into their protocols. $8,9,12$

The Department of Veteran's Affairs (VA) health care system has carried out large and medium-sized cohort studies over its long history ${ }^{13-16}$ that have focused on a wide range of topics including but not limited to the effects of specific occupational exposures, aging, and the effects of tobacco and other general exposures on a wide array of diseases. The VA patient population is well suited to large-scale longitudinal research for several reasons. The VA stores, updates, and accesses the health care records of 5.3 million patients ${ }^{17}$ through an electronic medical records system, and patients often remain in contact with the VA health care system over a long period of time. Although $95 \%$ of VA patients are male, they include a broad spectrum of other geographic and demographic groups.

Not all veterans are eligible for health care through the VA system. Eligibility for care (and participation in VA research) depends on a number of criteria including the nature of a veteran's discharge, length of military service, whether disabilities suffered are judged by the VA as being connected to service ("service-connected"), and income. ${ }^{18}$ The majority of VA patients do not receive all of their medical care from the VA system, and use other private or publicly funded care as well. ${ }^{19}$

In 2006, in order to increase understanding of genetic and nongenetic mechanisms of common diseases affecting both veteran and general populations, to develop preventive strategies, and to help predict pharmacogenetic responses to drug treatments, the VA established a Genomic Medicine Program (GMP). ${ }^{20}$ To support research in these areas, it proposed establishing a database of annotated clinical samples from consenting volunteer VA patients. The database would isolate and analyze DNA from participants' blood samples and link these genomic data to participants' electronic health records for epidemiologic analyses. A wide range of phenotypes relevant to both the veteran and general populations could be studied. 
Existing VA policies on tissue banking for human biological specimens vary depending on the nature of the consent obtained from participants, and where and by whom the samples and data are stored and analyzed. ${ }^{20}$ Samples and information could be coded and stripped of personal identifiers. The coding key could be retained by the VA, allowing for updates of participants' health records over time. ${ }^{20}$

To prepare for and design the GMP database, the VA established an external GMP Advisory Committee consisting of veterans' advocates and scientific experts. The Committee's charge is to "provide expert counsel about protecting veterans' privacy and establish a strong ethical foundation for VA's use of genetic information." 21

The creation of a large GMP research database whose participants permit ongoing updates with their VA and civilian medical histories could depend in part on acceptance by veterans. Understanding characteristics associated with veterans' support for establishment of such a resource and their willingness to participate is critical both to recruiting a large number of participants and to analyzing the resulting data, since demographic differences in participation rates that go unaccounted for might bias or limit generalizability of the research. ${ }^{22}$ Participants must be able to trust VA researchers to maintain their privacy and to conduct research with integrity. VA patients may be especially sensitive to violations of privacy in light of recent reports in the media about lapses in the security of medical records. ${ }^{23}$

A study of veterans who are members of a VA registry of amyotrophic lateral sclerosis (ALS) patients measured characteristics associated with their participation in a DNA biobank. ${ }^{22}$ Recent studies of veterans measured attitudes about the design of informed consent documents for VA clinical trials, ${ }^{24,25}$ and about their views on whether and how their medical records should be used in research. ${ }^{24}$ However, no comprehensive, direct examination of the general VA population's attitudes toward the specific goals and proposed design of the research database have been published. ${ }^{20}$ A national survey of veterans who use the VA health care system was conducted to provide quantitative measures of veterans' attitudes about the GMP.

Major findings of this survey are presented here in three sections: veterans' general support for establishment of a database for genomic research, including attitudes about genetic research; attitudes about veterans' personal willingness to participate in the study and factors associated with those attitudes; and opinions about various aspects of the design of the database.

\section{MATERIALS AND METHODS}

The survey was preceded by a series of nine focus groups held in VA medical centers in Atlanta, the Bronx, Denver, and San Antonio. Participants were diverse with respect to age, sex, race, income, education, years served and military experience, and degree of health care benefits they receive through the VA.

An 85-item online survey, qualified by The Johns Hopkins University Institutional Review Board as exempt (Application \# NA 00016472), was developed to collect data on the opinions of veterans who use the VA health care system about the development of the VA GMP's biobank (see Survey, Supplemental Digital Content 1, http://links.lww.com/A983). Survey questions asking participants to agree or disagree with statements of opinion about the proposed study were based on common responses and themes from the focus groups.

After determining eligibility and reading a description of the proposed study, survey participants were asked about their opinions on genomic research, aspects of establishing and par- ticipating in the study, including potential benefits and burdens, and how and by whom the data collected might be used. The survey concluded with several demographic questions related to participants' military service, use of the VA health care system, and personal history of volunteerism.

The survey was piloted between April 5 and April 8, 2008 in a group of 41 veterans randomly selected from the Knowledge Networks (KN) Panel described below to evaluate the length, logic, skip patterns, and wording of the survey. Feedback solicited from pilot participants indicated no problems with comprehension of the survey instrument. Median time to complete the 133 item pilot was 37 minutes. To reach the target survey length of 20 minutes, the instrument was pared down to 67 essential items related to the proposed database and 13 demographic questions. One advantage of using the KN Panel is that previously collected, banked demographic data are stored for all panelists. These demographic data are merged with panelists responses, and do not need to be asked during the survey, allowing more time for topical questions. The survey instrument, which is available online at http://www.dnapolicy.org/ resources/JHU_Veterans_Survey.pdf, includes an explanation and schematic diagram outlining the proposed design of the database study. Where necessary, definitions of terms were provided, and hyperlinks back to the definitions were added when a previously defined term was used later in the survey instrument.

Sample selection and online administration of the survey was managed by $\mathrm{KN}$. The sample was drawn from $\mathrm{KN}^{\prime} \mathrm{s}$ master panel, which includes 43,000 U.S. residents above the age of 18 . $\mathrm{KN}$ selects its master panel using list-assisted random digit dialing to provide a probability-based sample from which to draw. To decrease bias resulting from a "technology gap," people selected by KN to participate who do not have Internet access are given free Internet access and a WebTV appliance by KN. All members of the panel previously identified by $\mathrm{KN}$ as nonactive military $(n=4193)$ were contacted to participate and screened for eligibility. Those who responded that they had or do receive VA health or psychological care then were offered the online survey.

The main survey was fielded online between April 24 and May 5, 2008. Potential participants were e-mailed an invitation to participate, and nonresponders received one e-mail reminder after 3 days. Participants received the equivalent of $\$ 5$ for their time. After survey data were collected, prebanked information previously collected by $\mathrm{KN}$ on panel members' demographics and backgrounds was added to the data set.

\section{Analysis methods}

Data were sorted and prepared for analysis using SPSS software (SPSS Inc., Chicago, Ill). Support for the study and willingness to participate both were measured using 4-point Likert scales; two binary variables were created for analysis from these scales. People who said the database should definitely or probably be created were considered to support the study, and those who said it probably or definitely should not be created were considered not to support the study. Similarly, those who would definitely or probably participate were considered "willing" and those who probably or definitely would not participate were considered "unwilling." Data were analyzed using the SUDAAN software package (Version 9.0, Research Triangle Institute, Research Triangle Park, NC), which employs Taylor series linearization estimation of variance to correct for the survey-sampling scheme when judging hypothesis test results. Analyses were corrected for sampling strategy using SUDAAN's "WOR" (without replacement) design option. Multiple logistic regressions were used to examine demo- 
graphic factors and opinions associated with support and participation. Analyses that included the entire sample were weighted to the 2005 VA demographic benchmarks ${ }^{26}$ for gender, race and ethnic background, age, education, and region of the United States to reduce bias from sampling error.

\section{RESULTS}

Of the 4193 people initially contacted by KN, 3076 responded to the screening question for a response rate of $73 \%$. Of these, 931 (30\% of respondents) qualified to take the survey because they received some health or psychological care from the VA. In 2001, an internal VA survey estimated that $26 \%$ of veterans receive some or all of their health care from the VA. ${ }^{27}$ The margin of error on opinion estimates based on the sample of 931 is $\pm 3.4 \%$ after correcting for sampling design.

Distributions of gender, race, and ethnicity in the unweighted sample were similar to an internal study of VA demographics completed in $2005 .{ }^{21,26}$ The sample for the current study had a somewhat higher level of education, and included a larger proportion of people between the ages of 45 and 64 than expected based on VA demographic figures (see Table, Supplemental Digital Content 2, http://links.lww.com/A984). Weights seemed to be appropriately calculated-after weighting the data for gender, race and ethnicity, age, education, and region, frequencies of these demographic variables were similar to the 2005 VA survey benchmarks (see Table, Supplemental Digital Content 2, http://links.lww.com/A984).

To assess whether our sample was representative with respect to veterans using the VA health care system, we compared the distribution of service-connection ratings of our sample to 2005 VA data. The service-connection rating is a classification of a veteran's eligibility for care and disability benefits, based on the circumstances related to a veteran's disability. Given the survey question, we asked about respondents' service-connection rating, the most easily comparable figures are the percentage of respondents who had service-connected ratings greater than zero. The unweighted sample was very similar to the overall VA population with respect to the distribution of service-connected VA patients (see Supplementary Materials). Furthermore, after weighting for standard demographic variables, the distribution of service-connection ratings was even more closely aligned with VA statistics, even though we did not weight for service-connection.

Responding to questions about different behaviors that might serve as surrogates for altruism, $18 \%$ of respondents had donated blood in the past 5 years, $42 \%$ were registered as organ donors, and $30 \%$ had volunteered in some way to help other veterans.

\section{Veterans' support for the GMP database}

Immediately after participants viewed or read the description of the GMP database they were asked, "Based on what you just learned, do you think the Genomic Medicine Program should be done?" Eighty-two percent felt the database definitely (29\%) or probably (53\%) should be created although small numbers said probably not $(12 \%)$ or definitely not $(6 \%)$.

Near the end of the section of questions about the GMP database, after respondents were asked about different possible study requirements, benefits, burdens, data uses, and concerns, respondents were asked, "Now that you have had a chance to think more about the Genomic Medicine Program, do you think it should be done?" Overall, there was no significant difference between support at the beginning and end of the survey. At the end of the survey, $83 \%$ supported the biobank-32\% definitely and $51 \%$ probably thought it should be done, although $11 \%$ and $6 \%$ said it probably and definitely should not be done respectively. Three in four respondents did not change their opinion between the beginning and the end of the survey. Women $(+7 \%)$ and respondents over the age of $75(+5 \%)$ showed the greatest increases in support between the beginning and end of the survey, while black non-Hispanics $(-6 \%)$ and those unsatisfied with their VA care $(-2 \%)$ showed the largest decreases in support.

For subsequent analyses, the responses to the question about support for the database at the end of the survey were used, since these responses reflect participants opinions' after they had considered the set of questions posed during the survey.

High levels of support for the GMP database were observed across all demographic groups (Table 1). With the exceptions of black non-Hispanics and veterans whose first military service was during or after the Gulf War, more than $80 \%$ of every demographic group supported establishment of the database. In univariate models, being a blood donor, or a registered organ donor, or being more satisfied with VA care were all independently associated with higher levels of support. In a multiple logistic regression adjusting for the categories of gender, race or ethnic group, age, household income, and education that are found in Table 1, both satisfaction with the VA (OR 2.4, 95\% CI 1.2-2.7, $P=0.01$, comparing all satisfied to all unsatisfied) and being a blood donor (OR 2.9, 95\% CI 1.3-6.6, $P=0.009$ ) were independently associated with higher levels of support. No other demographic variables were significantly associated with support in multivariate analysis (Table 1).

Respondents also were asked several questions about their attitudes toward the GMP database. Most (86\%) agreed with the statement that they were curious about the influence of genes on health. A majority also agreed (61\%) or strongly agreed (23\%) with the statement that the proposed database would "lead to improved treatments, cures or lives saved for veterans," and four in five agreed that it was an important thing for the VA to do. However, 55\% agreed they would worry the project would take dollars away from other health care provided at the VA, and $53 \%$ worried that the study would not be able to recruit participants from all segments of the VA population.

\section{Veterans' willingness to participate in the GMP database}

Near the end of the questions about the GMP database, respondents were asked, "Based on what you know today, would you participate in the Genomic Medicine Program?" Overall, $71 \%$ said they definitely $(22 \%)$ or probably $(49 \%)$ would participate in the proposed database. Eleven percent said they definitely would not participate whereas $17 \%$ said they probably would not take part. Figure 1 shows the percentage of respondents willing to participate in possible components of the study.

As with general support for the study, majorities in all demographic groups were willing to participate (Table 1). However, there were significant differences in willingness to participate among several groups in Table 1. In a multiple logistic regression of demographic characteristics that treated willingness to participate as a binary dependent variable, adjusting for the other factors in Table 1, black non-Hispanics were significantly less likely to say they would participate than white non-Hispanics $(\mathrm{OR}=0.4,95 \% \mathrm{CI}=0.2-0.8, P=0.01)$, and strong dissatisfaction with VA care was associated with lower willingness to participate $(\mathrm{OR}=0.3,95 \% \mathrm{CI} 0.2-0.6, P=$ 0.0002 ). In contrast, Hispanics (OR 3.4, 95\% CI 1.0-11.3, $P=$ 
Table 1 Opinions on the proposed VA Genomic Medicine Program database, by demographic group, military service, and other veteran- and VA-related characteristics

\begin{tabular}{|c|c|c|c|c|}
\hline Demographic group & $N$ & $\begin{array}{l}\text { Weighted } \\
(\%)\end{array}$ & $\begin{array}{l}\% \text { Who said biobank probably } \\
\text { or definitely should be created }\end{array}$ & $\begin{array}{l}\% \text { Who would probably or } \\
\text { definitely participate }\end{array}$ \\
\hline \multicolumn{5}{|l|}{ Demographic group } \\
\hline Total & 931 & 100 & 82 & 71 \\
\hline Men & 869 & 93 & 84 & 72 \\
\hline Women & 62 & 7 & 83 & 66 \\
\hline White non-Hispanic & 746 & 80 & 86 & 74 \\
\hline Black non-Hispanic & 93 & 10 & 70 & 51 \\
\hline Hispanic (all races) & 36 & 4 & 84 & 82 \\
\hline Other non-Hispanic & 56 & 6 & 80 & 71 \\
\hline Age $18-44$ & 133 & 14 & 83 & $80^{a}$ \\
\hline Age $45-54$ & 143 & 15 & 83 & 75 \\
\hline Age $55-64$ & 248 & 27 & 85 & 73 \\
\hline Age $65-74$ & 230 & 25 & 82 & $65^{a}$ \\
\hline Age $75+$ & 177 & 19 & 86 & 69 \\
\hline HH income under $\$ 25,000$ & 247 & 27 & 86 & 73 \\
\hline$\$ 25,000-\$ 49,999$ & 291 & 31 & 80 & 65 \\
\hline$\$ 50,000-\$ 74,999$ & 198 & 21 & 84 & 76 \\
\hline Over $\$ 75,000$ & 196 & 21 & 85 & 76 \\
\hline $0-12$ years of education & 368 & 39 & 83 & 64 \\
\hline Some college & 343 & 37 & 83 & 76 \\
\hline B.A. & 219 & 24 & 87 & 78 \\
\hline \multicolumn{5}{|l|}{ Service and VA characteristics } \\
\hline Total & 931 & 100 & 82 & 71 \\
\hline \multicolumn{5}{|c|}{ Satisfied with VA care (11 missing) } \\
\hline Strongly agree & 291 & 32 & 90 & 76 \\
\hline Agree & 450 & 49 & 85 & 73 \\
\hline Disagree & 116 & 13 & 77 & 76 \\
\hline Strongly disagree & 64 & 7 & 66 & 44 \\
\hline \multicolumn{5}{|c|}{ Percent of care from VA (4 missing) } \\
\hline $0-25$ & 442 & 48 & 82 & 66 \\
\hline $25-50$ & 92 & 10 & 80 & 75 \\
\hline $50-99$ & 111 & 12 & 84 & 86 \\
\hline 100 & 282 & 30 & 88 & 74 \\
\hline \multicolumn{5}{|l|}{ Service connected? } \\
\hline Yes & 363 & 39 & 85 & 76 \\
\hline No & 386 & 42 & 84 & 69 \\
\hline Don’t know & 180 & 19 & 81 & 67 \\
\hline \multicolumn{5}{|c|}{ Service connection rating (47 missing) } \\
\hline $50 \%$ & 104 & 11 & 85 & 75 \\
\hline $30-40 \%$ & 68 & 7 & 86 & 82 \\
\hline
\end{tabular}


Table 1 (Continued)

\begin{tabular}{|c|c|c|c|c|}
\hline Demographic group & $N$ & Weighted (\%) & $\begin{array}{l}\% \text { Who said biobank probably or } \\
\text { definitely should be created }\end{array}$ & $\begin{array}{l}\% \text { Who would probably or } \\
\text { definitely participate }\end{array}$ \\
\hline $10-20 \%$ & 117 & 13 & 85 & 72 \\
\hline $0 \%$ & 28 & 3 & 93 & 90 \\
\hline VSO member & 359 & 39 & 86 & 73 \\
\hline Not a VSO member & 572 & 61 & 82 & 70 \\
\hline \multicolumn{5}{|l|}{ First era served } \\
\hline Korea or earlier & 220 & 24 & 86 & 70 \\
\hline Between Korea and Vietnam & 105 & 11 & 82 & 65 \\
\hline Vietnam & 359 & 39 & 83 & 71 \\
\hline After Vietnam & 139 & 15 & 87 & 75 \\
\hline Gulf war I or later & 98 & 11 & 77 & 77 \\
\hline Combat experience & 433 & 47 & 86 & 74 \\
\hline Noncombat experience & 494 & 53 & 82 & 70 \\
\hline Environmental exposure $^{b}$ & 326 & 35 & 82 & 78 \\
\hline No exposure & 586 & 65 & 82 & 68 \\
\hline
\end{tabular}

${ }^{a}$ Response to question asked at end of the survey.

${ }^{b}$ Respondents were asked, "Do you believe you were ever exposed to environmental hazards such as Agent Orange, chemical warfare agents, ionizing radiation, or other potentially toxic substances?"

VSO, veteran service organization.

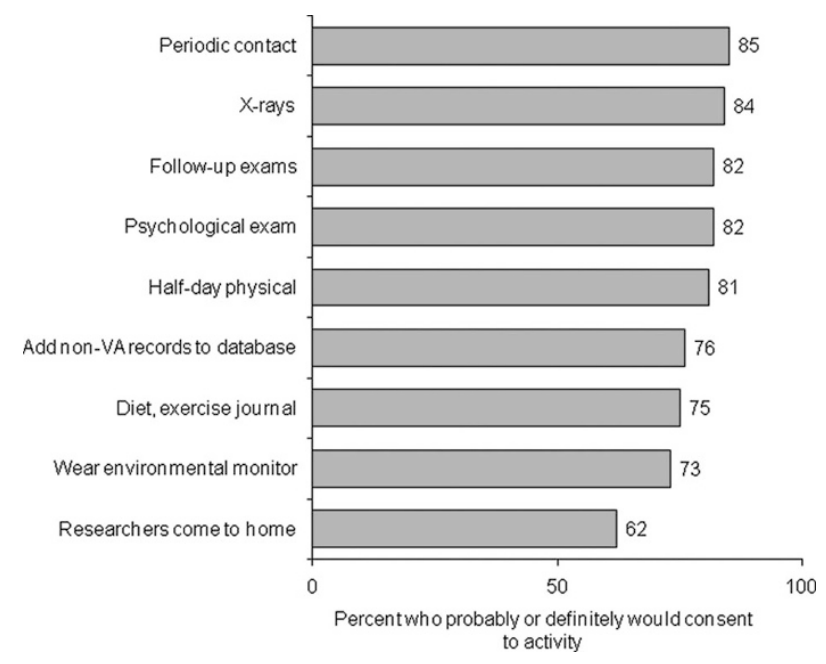

Fig. 1. Percent of survey respondents who said they probably or definitely would consent to various components of the study proposed by the Veterans' Administration Genomic Medicine Program $(n=931)$.

0.04), those that receive more than a quarter of their health care from the VA $(\mathrm{OR}=1.9,95 \% \mathrm{CI} 1.2-3.0, P=0.01)$ and those with one or more years of college $(\mathrm{OR}=2.4,95 \%$ CI $1.4-3.9$, $P=0.0002$ ) were more likely to say they would take part.

In addition, four variables that may be indicators of respondents' altruistic beliefs and practices were independently associated with willingness to participate adjusting for the demographic factors above. Being a registered organ donor and recent experience as a blood donor both were associated with increased likelihood of willingness to participate (adjusted $\mathrm{OR}=1.9,95 \%$ CI $1.2-3.3 P=0.01$ and adjusted $\mathrm{OR}=2.7$, 95\% CI 1.4-5.2, $P=0.004$, respectively). Two-thirds of respondents said they would be less likely to join the study if they did not receive research results back; these people also were significantly less likely to say they would participate $(67 \%)$ compared with those who said it would not matter if they did not receive results back (82\%), after adjusting for the demographic factors and other altruism-related variables $(\mathrm{OR}=0.5$, 95\% CI $0.3-1.0, P=0.04)$. Similarly, people who said that receiving monetary compensation for their time would be very or somewhat important in their decision to participate were less likely to participate $(64 \%)$ than those who said compensation would not be very important, or not important at all $(83 \%$; adjusted OR $=2.0,95 \%$ CI 1.2-3.3, $P=0.006)$. When these four factors were added to the regression model, the difference between Hispanics and respondents of other races or ethnicities with respect to willingness to participate was not significant. All of the other associations reported above between demographic characteristics and willingness to participate remained significant.

Several factors related to respondents' military service were examined, including the degree of service connection, membership in a veterans' service organization, the number of years served, the era in which a person first served, and whether he or she was exposed to combat or environmental hazards during his/her service. None were associated with willingness to participate.

Veterans also were asked about various implications of participation in the GMP study. Four in five agreed with the statement that participating would make them feel like they were helping other veterans. Although $78 \%$ agreed that partic- 
ipation would be easy, 37\% agreed that participating would make them feel like a guinea pig. In the focus groups veterans were asked about different aspects of informed consent and responded using terms like "agreement" and "contract," suggesting some referred a two-way commitment between researcher and participant that might differ in some ways from an informed consent document. We came up with the term "research agreement" to capture this idea, but did not explain the term further to participants. If respondents were to participate, more than $97 \%$ said it would be somewhat or very important that there be a research agreement signed by both researchers and participants, and that serious consequences would exist for researchers who violate this agreement. Most said it would be important that it be illegal for insurers (95\%) and law enforcement $(87 \%)$ to get their information from the database.

\section{Opinions on aspects of database design}

Survey respondents were asked several questions about the privacy of their medical and genetic information, assuming that they were participating in the GMP study. If respondents were to participate, $98 \%$ said it would be somewhat or very important that the VA develop safeguards to protect their information. Three in four said having their privacy protected was very important to them, and another $17 \%$ felt it was somewhat important. Those with more education or higher household income, younger participants, those beginning their service during or after Vietnam, those less satisfied with the VA, and those who are service-connected were all more likely to say protecting their privacy was very important. Half of respondents were very or somewhat concerned about the government having their samples and information and $47 \%$ were concerned that information collected by the study could be used against them.

Concerns about privacy were strongly related to whether respondents felt that a key linking their name to de-identified samples should be kept to allow updating of medical data in the database. Three in four participants felt that a key should be kept. Table 2 shows that protection of privacy was still important to people who supported keeping a key. However, people who supported keeping a key were far less concerned that study information would be used against them, or that the government would have their samples.

When respondents were asked to choose from three possible models of informed consent that might be offered to those participating in the study, their preferences were split. Slightly more people $(47 \%)$ preferred to give a blanket consent for use of all research approved by the GMP than preferred to give separate consent for each individual research project undertaken using the database (43\%). The remaining $10 \%$ would prefer to select broad categories of research they find acceptable at the outset of the study.

Veterans also were asked whether various kinds of researchers outside the VA system should be able to use the collected data and samples. Granting access to the database to U.S. academic researchers was favored by $80 \%$ of participants, to other governmental researchers by $71 \%$, to researchers in U.S. pharmaceutical companies by $54 \%$, and to academic researchers in other countries by $43 \%$ of participants. Those who were more willing to participate were also more supportive of broader access to the database by various users.

The types of research for which respondents would allow their samples and information to be used are found in Figure 2. Respondents showed high levels of approval for research on most conditions and traits that they were asked about, including posttraumatic stress disorder.

Finally, respondents were asked several questions about the return of individual research results to study participants. First, the idea of individual research results was defined as information about whether a person in the study had a specific genetic, environmental, or lifestyle risk factor identified using the GMP database. It was explained that generally, such data are not returned to research participants, unless the research is conducted in a clinical laboratory that is certified to give clinical results. Participants then were asked to assume that tests would not be performed in a certified laboratory, and not returned to participants. Under these circumstances, $68 \%$ said they would be less likely to participate, $30 \%$ said it would not matter in their decision, and $2 \%$ said they would be more willing to participate. Respondents then were asked to assume that the research was performed in a certified laboratory and asked about their preferences with respect to the return of research results. It was not explained to participants that some research results would not yet be validated, that some results would be for genes conferring low additional risks for disease, or that some results might not indicate any additional actions to prevent or treat a disease. Desire for results under these circumstances was high: 9 of 10 agreed that they would want to know all of their research results. The ability to choose which research results a person would get back was important to $69 \%$ of participants.

\section{DISCUSSION}

The survey data show that there is widespread support among the VA population to establish a GMP database of linked genetic and clinical information for the study of diseases pertinent to the VA patient population. Our finding that $84 \%$ of veterans who receive care through the VA support establishment of this database is comparable to a smaller study of VA patients opinions on the use of their medical records in research, ${ }^{24}$ where veterans showed a similarly high level of support $(89 \%)$ for general medical records research. As in our survey, despite a high level of support for such research, many participants in the medical records study wanted control over how their records would be used-39\% wanted to provide consent for each study, while $35 \%$ would provide blanket consent to researchers. ${ }^{24}$

Table 2 Privacy concerns among those who felt a key linking participants to samples should and should not be kept

Percent who believe that:

Opinion about whether Protecting my privacy is I would be concerned the information from I would be concerned about the government a key should be kept very important to me the program could be used against me having my samples and information

\begin{tabular}{llll}
\hline Key should be kept & 73 & 40 & 42
\end{tabular}




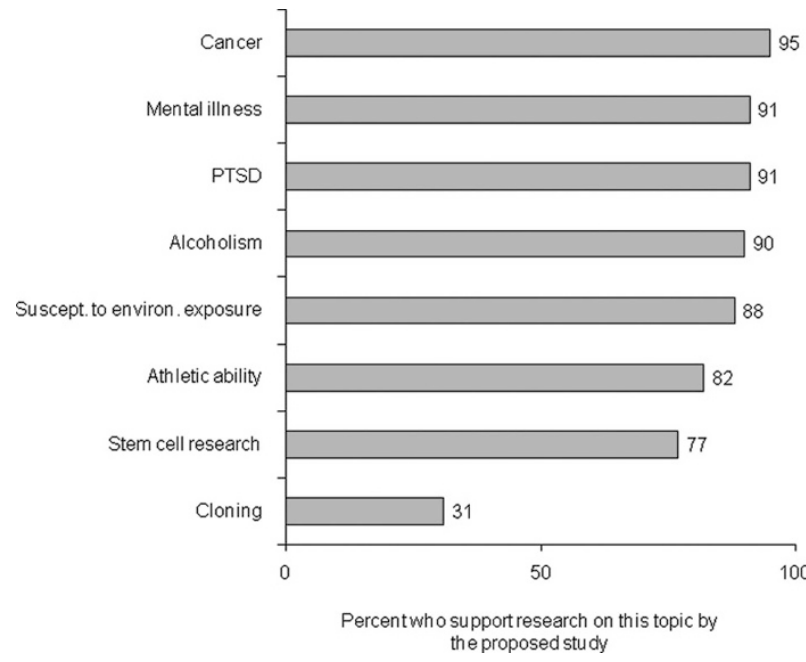

Fig. 2. Support for research on various topics using data from the proposed Genomic Medicine Program study, among surveyed Veterans Affairs (VA) health care users $(n=913)$.

Although $55 \%$ of respondents were concerned about the VA using health care resources for the study, much larger majorities agreed that the study might directly benefit veterans. Four of five felt that a database of genetic and medical information eventually would lead to improvements in veterans' health, and the same number agreed that participating would make them feel like they were helping other veterans.

The high level of support for the creation of large DNA biobanks has been echoed in other surveys of general populations and prospective cohort study participants. In a 2008 survey of the U.S. general public, ${ }^{28} 84 \%$ said that a large national cohort study of genes environment and lifestyle should definitely or probably be done. Support for longitudinal genetic research was even higher in surveys of Vanderbilt University Medical Center patients eligible to participate in a new biobank $(88 \%)^{29}$ and of participants in a case-control study of colon cancer genetics $(95 \%){ }^{30}$

The fraction of respondents in our survey who said they would be willing to participate $(71 \%)$ also is comparable to the high end of the range of $38-78 \%$ observed in other U.S. surveys of general publics asked about donating blood or DNA to a future biobank or cohort study. ${ }^{28,31-36}$ Significantly, more veterans were willing to participate than a sample of the U.S. general public surveyed in 2008, where $60 \%$ were willing to take part in a nationwide longitudinal study of genes, lifestyle, and environment. ${ }^{28}$ However, in the general public survey, respondents were asked about participating in a 10-year study that explicitly required more of participants than the description of the biobank used in the veterans' survey.

In a clinical study of 1020 veterans already enrolled in a VA registry for ALS, $85 \%$ consented to participate in a VA-sponsored DNA bank. This model of banking DNA samples from participants in ongoing VA clinical trials, which has been proposed by VA researchers, ${ }^{37}$ could result in very high rates of consent. Studies of civilians already enrolled in research protocols have reported rates of consent to provide a blood or DNA sample for storage and research between 85 and $92 \% .^{38-42}$

People's responses on a survey about their willingness to participate in a hypothetical study should not be construed as estimates of the actual percentage of people who would participate. Survey responses about future behavior do not always correlate with actual behaviors. This study is likely to provide valid estimates of veterans' support for the study and of the study design factors that might influence participation, but is less likely to be accurate in estimating absolute participation rates. In addition, people in the sample studied here (as well as other survey samples) may be biased in their responses to questions about their willingness to participate in research requiring them to provide personal information, since all survey participants have, by default, already agreed to participate in the KN panel and provide other personal data. However, high actual participation rates by veterans in other research studies suggests that this bias may be small.

A good deal of research about participation in genetic studies, and research in general focuses on who is motivated to participate, and identifies or assesses various strategies to improve recruitment. ${ }^{34,43}$ Although some differences were noted in this survey, levels of both support and willingness to participate were consistent across age, income, education, and gender, and most demographic characteristics specific to military service. Support and willingness to participate were not associated with respondents' length of service, their stated service connection rating, membership in a Veteran's Service Organization, or the era in which they first served.

We did observe significantly lower willingness to participate in the GMP database among black non-Hispanics compared with white non-Hispanics and Hispanics. Although there are known racial differences in the use of VA health services, ${ }^{44}$ and the degree of VA health care use was associated with willingness to participate in this study, differences in the use of care did not explain lower willingness among black non-Hispanics in this survey. As in other studies, ${ }^{29,30,38,39}$ willingness to participate in the study was lower than in whites and Hispanics, but still was favored by a small majority of black non-Hispanics. Lower participation by black non-Hispanics in other genetic and longitudinal research settings also has been reported in a pilot study where participants in an ALS registry were asked to donate blood for genetic research, ${ }^{22}$ in studies of Gulf War era veterans ${ }^{45}$ as well as in research outside the VA. ${ }^{34,41,43,46}$ However, recruitment efforts for other large VA cohort studies of former military personnel ${ }^{16,47,48}$ and a survey of the general U.S. public ${ }^{28}$ have found no differences in black-non-Hispanics' actual participation rates or stated willingness to participate in similar types of research. ${ }^{49}$

The lack of association between the characteristics of military service we queried and support or willingness to participate in the GMP database also was noteworthy. Although various aspects of military service were not associated with views about the study, respondents' relationships with the VA health care system were associated with willingness to participate. Veterans who received more than a quarter of their care from the VA were significantly more likely to say they would participate. This could be due to familiarity with the VA, the convenience of participating in a study at a site they visit for other reasons, or the feeling that they are dependent on or indebted to the VA health care system and thus are more willing to "give back." Conversely, low willingness to participate among respondents who were strongly dissatisfied with their VA health care may be due to the relative inaccessibility or inconvenience of VA care for some people, to a lack of sense of loyalty or ownership, or to distrust in any effort associated with the VA system.

We observed that four distinct variables related to altruism (history of donating blood, registration as an organ donor, being less likely to participate without return of research 
results, and importance of receiving compensation for their time) were independently associated with respondents' willingness to participate. This observation suggests that some level of experience with or belief about altruistic behaviors may influence decisions about whether to participate in a biobank, and appeals to these tendencies may be important in recruiting participants.

Public eagerness for genetic information in the form of research results is unsurprising in an environment where genetic research is widely believed to be beneficial, and where genetic tests are being sold directly to consumers. ${ }^{5,50}$ Other studies of public opinion have shown wide support for the return of research results from biobanks. ${ }^{28,42,51-53}$ However, caution must be used when interpreting the data presented here, on research results, since we did not ask participants whether they would want to know about associations that have not been replicated, associations that indicate small increased risks of disease, or associations with unclear clinical utility. Further research is needed to determine the criteria that define what the public actually wants when it refers to research results, and what should be done with results that do not meet these criteria.

The promise of new treatments and preventative measures, and respondents' curiosity about the role of genes in their health and the health of their relatives and fellow veterans, resonate as important factors that largely seem to outweigh concerns about privacy, mistreatment, or the use of limited VA health-care dollars. Although these concerns are real and must be addressed, the surveyed population seems to believe that the benefits of a GMP database will largely outweigh the burdens, if study designers can protect participants' information from misuse and offer as much transparency as possible.

\section{ACKNOWLEDGMENTS}

This work was funded by the Veterans Health Administration and the National Human Genome Research Institute under Grant number HG004206-01S, Supplement to a Public Consultation to Inform the Design of Possible Large-Scale Studies of Genes and Environment in Common Disease. The authors would like to thank Joel Kupersmith, MD, Chief Research and Development Officer, Veterans Health Administration for helpful discussions, as well as the survey participants for their time.

\section{REFERENCES}

1. McCarty CA, Wilke RA, Giampietro PF, Wesbrook SD, Caldwell C. Marshfield clinic personalized medicine research project (PMRP): design, methods and recruitment for a large population-based biobank. Personalized Med 2005;2:49.

2. National Children's Study. National Children's Study Homepage. Available at: http://www.nationalchildrensstudy.gov/. Accessed June 18, 2008.

3. UK Biobank. UK biobank homepage. Available at: http://www.ukbiobank. ac.uk/. Accessed June 18, 2008.

4. Kaiser Permanente. Division of research: Research program on genes, environment, and health. Available at: http://www.dor.kaiser.org/studies/ rpgeh/index.html. Accessed February 16, 2009.

5. 23 andMe. 23andMe press release - 23andMe launches consumer-enabled research program to actively engage individuals in genetics research. Available at: http://www.23andme.com/about/press/20080529/. Accessed June 25, 2008.

6. Roden D, Pulley J, Basford M, et al. Development of a large-scale deidentified DNA biobank to enable personalized medicine. Clin Pharmacol Ther 2008;84:362-369.

7. North KE, Howard BV, Welty TK, et al. Genetic and environmental contributions to cardiovascular disease risk in American Indians: the strong heart family study. Am J Epidemiol 2003;157:303-314.

8. Howard BV, Devereux RB, Cole SA, et al. A genetic and epidemiologic study of cardiovascular disease in Alaska Natives (GOCADAN): design and methods. Int J Circumpolar Health 2005;64:206-221.

9. Splansky GL, Corey D, Yang Q, et al. The third generation cohort of the National Heart, Lung, and Blood Institute's Framingham Heart Study: design, recruitment, and initial examination 190. Am J Epidemiol 2007;165: $1328-1335$.

10. McCarty CA, Nair A, Austin DM, Giampietro PF. Informed consent and subject motivation to participate in a large, population-based genomics study: the Marshfield Clinic Personalized Medicine Research Project. Community Genet 2007;10:2-9.

11. Gulcher J, Stefansson K. Population genomics: laying the groundwork for genetic disease modeling and targeting 64. Clin Chem Lab Med 1998;36:523-527.

12. McQuillan GM, Porter KS, Agelli M, Kington R. Consent for genetic research in a general population: the NHANES experience. Genet Med 2003;5:35-42.

13. Cohen BM, Cooper MZ, eds. Follow-Up Study of World War II Prisoners of War: VA Medical Monograph. Washington, DC: U.S. Government Printing Office, 1955.

14. Nefzger MD. Follow-up studies of World War II and Korean War prisoners: I. study plan and mortality findings. Am J Epidemiol 1970;91:123-138.

15. Norman JE, Robinette CD, Fraumeni JF. The mortality experience of Army World War II chemical processing companies. J Occup Med 1981;23:818-822.

16. Ryan MAK, Smith TC, Smith B, et al. Millenium cohort: enrollment begins a 21-year contribution to understanding the impact of military service. J Clin Epidemiol 2007;60:181-191.

17. Department of Veterans Affairs. Veterans Health Administration. Veterans aging cohort study. Available at: http://www.vacohort.org/. Accessed September 3, 2008.

18. United States Department of Veteran's Affairs. Health care eligibility and enrollment for veterans. Available at: http://www.va.gov/healtheligibility/ eligibility/. Accessed September 11, 2008

19. Shen Y, Hendricks A, Zhang S, Kazis LE. VHA enrollees' health care coverage and use of care. Med Care Res Rev 2003;60:253-267.

20. Przygodzki RM. Genomic medicine program. Available at: http://www. research.va.gov/programs/pride/conferences/docs/accountability/GenomicMed-Program.ppt. Accessed September 4, 2008.

21. U.S. Department of Veteran's Affairs. VA research and development genomic medicine fact sheet. Available at: http://www.research.va.gov/resources/pubs/ docs/genomic_fact_sheet.pdf 2008. Accessed February 16, 2009.

22. DiMartino L, Allen KD, Kasarskis E, et al. Characteristics associated with participation in DNA banking: the national registry of veterans with ALS. Contemp Clin Trials 2007;28:572-582.

23. Lubell J. VA theft included medical data. Groups concerned information could be used to discriminate against vets. Mod Healthc 2006;36:12.

24. Damschroder LJ, Pritts JL, Neblo MA, Kalarickal RJ, Creswell JW, Hayward RA. Patients, privacy and trust: patients' willingness to allow researchers to access their medical records. Soc Sci Med 2007;64:223-235.

25. Peduzzi P, Guarino P, Donta ST, Engel CC Jr, Clauw DJ, Feussner JR. Research on informed consent: investigator-developed versus focus groupdeveloped consent documents, a VA cooperative study. Control Clin Trials 2002;23:184-197.

26. Department of Veterans Affairs Office of the Assistant Deputy Under Secretary for Health Policy and Planning. 2005 survey of veteran enrollees' health and reliance upon VA. Available at: http://www1.va.gov/vhareorg/ reports/FinalSOE_05.pdf. Accessed February 16, 2009.

27. Department of Veterans Affairs Office of Policy and Planning. National survey of veterans 2001. Washington, DC, 2001.

28. Kaufman D, Murphy J, Scott J, Hudson K. Subjects matter: a survey of public opinions about a large genetic cohort study. Genet Med 2008;10:831-839.

29. Pulley JM, Brace MM, Bernard GR, Masys DR. Attitudes and perceptions of patients towards methods of establishing a DNA biobank. Cell Tissue Bank 2008;9:55-65

30. Henderson G, Garrett J, Bussey-Jones J, Moloney ME, Blumenthal C, Corbie-Smith G. Great expectations: views of genetic research participants regarding current and future genetic studies. Genet Med 2008;10:193-200.

31. Goldman RE, Kingdon C, Clark MA, et al. Rhode islanders' attitudes towards the development of a statewide genetic biobank. Personalized Medicine 2008;5:339-359.

32. Buchwald D, Mendoza-Jenkins V, Croy C, McGough H, Bezdek M, Spicer P. Attitudes of urban American Indians and Alaska Natives regarding participation in research. J Gen Intern Med 2006;21:648-651.

33. Wong ML, Chia KS, Yam WM, Teodoro GR, Lau KW. Willingness to donate blood samples for genetic research: a survey from a community in Singapore. Clin Genet 2004;65:45-51.

34. Wang SS, Fridinger F, Sheedy KM, Khoury MJ. Public attitudes regarding the donation and storage of blood specimens for genetic research. Community Genet 2001;4:18-26.

35. Halbert $\mathrm{CH}$, Gandy $\mathrm{OH}$ Jr, Collier A, Shaker L. Intentions to participate in genetics research among African American smokers 142. Cancer Epidemiol Biomarkers Prev 2006;15:150-153.

36. Davis MD, Clark SJ, Singer DC, Tarini BA. Genetic testing and DNA biobanks - for whom, and when? National Poll on Children's Health C.S. Mott Children's Hospital, 2007;1:1 
37. Lavori PW, Krause-Steinrauf H, Brophy M, et al. Principles, organization, and operation of a DNA bank for clinical trials: a Department of Veterans Affairs cooperative study. Control Clin Trials 2002;23:222-239.

38. Chen DT, Rosenstein DL, Muthappan P, et al. Research with stored biological samples: what do research participants want? Arch Intern Med 2005; 165:652-655.

39. McQuillan GM, Pan Q, Porter KS. Consent for genetic research in a general population: an update on the National Health and Nutrition Examination Survey experience. Genet Med 2006;8:354-360.

40. Malone T, Catalano PJ, O'Dwyer PJ, Giantonio B. High rate of consent to bank biological samples for future research: the Eastern Cooperative Oncology Group experience. J Natl Cancer Inst 2002;94:769-771.

41. Moorman PG, Skinner CS, Evans JP, et al. Racial differences in enrollment in a cancer genetics registry. Cancer Epidemiol Biomarkers Prev 2004;13: 1349-1354.

42. Wendler D, Emanuel E. The debate over research on stored biological samples: what do sources think? Arch Intern Med 2002;162:1457-1462.

43. Sterling R, Henderson GE, Corbie-Smith G. Public willingness to participate in and public opinions about genetic variation research: a review of the literature. Am J Public Health 2006;96:1971-1978.

44. Damron-Rodriguez J, White-Kazemipour W, Washington D, Villa VM, Dhanani S, Harada ND. Accessibility and acceptability of the Department of Veterans Affairs health care: diverse veterans' perspectives. Mil Med 2004; 169:243-250.
45. Kang HK, Mahan CM, Lee KY, Magee CA, Murphy FM. Illnesses among United States veterans of the Gulf War: a population-based survey of 30,000 Veterans. J Occup Environ Med 2000;42:491-501.

46. Neidich AB, Joseph JW, Ober C, Ross LF. Empirical data about women's attitudes towards a hypothetical pediatric biobank. Am J Med Genet A 2008;146:297-304.

47. Reiber GE, Boyko EJ. Diabetes research in the Department of Veterans Affairs. Diabetes Care 2004;27(suppl 2):B95-B98.

48. Reiber GE, Au D, McDonell M, Fihn SD. Diabetes quality improvement in Department of Veterans Affairs ambulatory care clinics: a group-randomized clinical trial. Diabetes Care 2004;27(suppl 2):B61-B68.

49. Wendler D, Kington R, Madans J, et al. Are racial and ethnic minorities less willing to participate in health research? PLoS Med 2006;3:e19.

50. Navigenics Inc. Navigenics homepage. Available at: http://www.navigenics.com. Accessed August 6, 2008

51. Godard B, Marshall J, Laberge C. Community engagement in genetic research: results of the first public consultation for the Quebec CARTaGENE project. Community Genet 2007;10:147-158.

52. Hoeyer K, Olofsson BO, Mjorndal T, Lynoe N. Informed consent and biobanks: a population-based study of attitudes towards tissue donation for genetic research. Scand J Public Health 2004;32:224-229.

53. Fernandez CV, Santor D, Weijer C, et al. The return of research results to participants: pilot questionnaire of adolescents and parents of children with cancer. Pediatr Blood Cancer 2007;48:441-446. 